\title{
Em torno de um pensamento oxunista: İyá descolonizando lógicas de conhecimento
}

\author{
On an osunist thought: \\ İyá decolonizing logics of knowledge
}

WANDERSON FLOR DO NASCIMENTO (Da

\section{Resumo}

Este artigo objetiva discutir possibilidades de descolonização das lógicas de conhecimento a partir da proposta da socióloga e epistemóloga iorubá Oyèrónkẹ Oyěwùmí, buscando posicionar sua abordagem do oxunismo, da instituição İyá e do conceito de Matripotência como possibilidades de pensar maneiras para o trabalho com as filosofias africanas que não resultem em uma reprodução de uma lógica ocidentocêntrica no estudo e ensino dessas filosofias. Perseguindo esse objetivo, o trabalho definirá o que entende por lógicas de conhecimento para, em seguida, discutir o modo como a autora iorubá compreende o que significa descolonização. No momento seguinte apresentamos como, a partir da proposta do oxunismo de Oyěwùmí, é possível advogar um pensamento oxunista e pensar as categorias de İyá e Matripotência como adquirindo sentido nesse modo de pensar. O texto é um convite para pensarmos possibilidades não excludentes de reflexão para que não apaguemos as lógicas africanas de conhecimento, mesmo quando nos disponibilizamos, ainda que de boa vontade, a pensar as filosofias africanas.

Palavras-chave: Epistemologia. Filosofia Africana. Descolonização. Matripotência. Oyèrónkẹ Oyěwùmí.

\section{Abstract}

This paper aims to discuss possibilities of decolonization of logics of knowledge based on the proposal of the Yoruba sociologist and epistemologist Oyèrónké Oyèwùmi, seeking to position her approach to osunism, the İyá institution and the concept of

a Universidade de Brasília (UnB), Brasília, DF, Brasil. Doutor em Bioética, e-mail: wandersonflor@unb.br 
Matripotency, as possibilities of thinking ways to work about African philosophies that do not result in a reproduction of a Westocentric logic in the study and teaching of these philosophies. Based on this goal, the work will define what it understands as logics of knowledge, and then discuss how the Yoruba author understands what decolonizing means. Then we will present how, based on Oyèwùmi's proposal of osunism, it's possible to advocate an osunist thought and think of the categories of İyá and Matripotency as acquiring meaning through this way of thinking. This text is an invitation to think about non-excluding possibilities for reflection so that we do not erase African logics of knowledge, even when we are willing, even if willingly, to think about African philosophies..

Keywords: Epistemology. African Philosophy. Decolonizing. Matripotency. Oyèrónkẹ Oyěwùmí.

\section{Introdução}

O trabalho com as filosofias africanas, mesmo quando superados os famigerados problemas sobre sua existência e sua "identidade", enfrenta uma série de desafios. Um dos mais importantes deles é aquele que instaura o fazer das filosofias africanas no meio de lógicas ocidentocêntricas de conhecimento, por meio das quais universalizações de posições locais e binarismos lógicos, ontológicos e epistêmicos nos aparecem como diretivas inevitáveis para o pensamento. Isso nos levaria a praticar as filosofias africanas do mesmo modo como as filosofias ocidentais têm sido feitas na modernidade, como se esse fosse o caminho natural, e único legítimo, para a prática filosófica.

Por lógicas de conhecimento entendemos, aqui, o conjunto de orientações que dão forma aos modos de produzir conhecimento, mobilizando ferramentas de teorização, esquemas de argumentação, pressuposições em torno de relações entre a teoria e o vivido envolvidas na produção do conhecimento, que determinam as maneiras como o que pensamos se relaciona com a história em toda a sua multiplicidade de aberturas. Desta forma, as lógicas de conhecimento não se reduzem, a princípio, aos temas e problemas com os quais o conhecimento se enfrenta, mas àquilo que faz com que algo possa ou deva ser problematizado e tematizado - e em como essa tematização e essa problematização podem se dar. Assim, as lógicas de conhecimento são solos culturais que permitem a inteligibilidade de modos de produção epistêmicos, indicando ambiências epistemológicas nas quais o conhecimento adquire sentido.

Este desafio de lidar com as filosofias africanas por meio das lógicas de conhecimento ocidentocêntricas se mostra intenso em função de sermos herdeiras de 
lógicas coloniais do poder e dos modos como essas lógicas se desdobraram - e demandaram - em específicas maneiras de produzir conhecimentos que, de alguma maneira, legitimem os modos como funciona o poder. Essas lógicas coloniais de poder alimentam e são alimentadas pelas lógicas de conhecimento de uma determinada sociedade. A colonização moderna não apenas possibilitou que alguns povos subjugassem econômica e politicamente outros, como também necessitou que modos de pensar, de conhecer se transformassem a serviço desse empreendimento colonial, promovendo, assim, não apenas hierarquias de poder, mas também hierarquias das maneiras e possibilidades de conhecer e hierarquias dos conteúdos do conhecimento.

Os estudos críticos sobre a colonialidade têm chamado a atenção para o fato de que os processos políticos de colonização são relacionados internamente com a colonização do imaginário e da subjetividade, de modo que o exercício do poder colonial é também um exercício de afirmação de um jeito de ser no mundo e de conhecer esse mundo vivido (NDLOVU-GATSHENI, 2013). Essa colonização seja política, do imaginário ou subjetiva — opera a partir de uma espécie de gramática social organizada em torno do racismo que, fundamentalmente, captura a diferença em hierarquias opressivas, distribuindo de modo desigual os lugares de poder, de imaginação, de ser, de agir e de conhecer.

Precisamos estar atentas a esse fenômeno para que não reproduzamos, nos estudos e ensino das filosofias africanas, a operação desta lógica colonial do conhecimento. Lógicas que fazem com que se capture a experiência de pensamento filosófica africana nessa maneira hierárquica de pensar como o conhecimento é produzido e transmitido, o que finda por desconsiderar o que as próprias experiências históricas africanas produziram no decorrer dos tempos.

Diante deste risco e cenário — que pode resultar em trabalhar com as filosofias africanas como se fossem um capítulo da história "universal" da filosofia, fazendo com que as matrizes ocidentais coloniais sigam prevalecendo hegemonicamente - a proposta deste artigo é discutir — a partir da abordagem da socióloga e epistemóloga iorubá, nascida na Nigéria, Oyèrónkẹe Oyěwùmí (1997, 2016a, 2016b) — uma experiência de problematização dessa hegemonia ocidentocêntrica nos estudos africanos, dos quais as filosofias africanas são parte. Assim, por meio do trabalho 
desta sociologia do conhecimento que baseia a análise epistemológica de Oyěwùmí, buscamos trazer alguns elementos de questionamento sobre o que fazemos quando atuamos no campo da discussão sobre as filosofias africanas.

Ao articular algumas das ideias trazidas pelo trabalho de Oyěwùmí, buscamos abrir um campo de problematização para o nosso fazer filosófico em torno das filosofias africanas, nesta nossa experiência diaspórica, não tanto apostando em que estaremos mais próximas de um pensamento ou de uma lógica de conhecimento "verdadeiramente" africana, mas para que não contribuamos para o apagamento das experiências africanas mesmo quando nos coloquemos a investigar as filosofias produzidas no ou desde o continente negro. E, com isso, pensamos em experimentar um dos caminhos possíveis a partir dos quais seja possível pensar na descolonização das lógicas de conhecimento com o que muitas vezes operamos sem problematizá-las.

Com este intuito, o texto discutirá brevemente o que a autora nos apresenta como a proposta de descolonização em sua empreitada epistemológica para, em seguida, partindo de sua proposta de um oxunismo (2016b) como um movimento que também perpasse o conhecimento, discutir o modo como a autora entende que a categoria İyá, central para sua discussão, nos aponta um caminho possível que enfrente as trilhas coloniais que insistem em perseguir nosso pensamento quando estamos interessadas e interessados em investigar as experiências africanas.

\section{Descolonizar?}

As sociedades que experimentaram a colonização sofreram muitos efeitos nocivos, alguns psicológicos, alguns linguísticos e alguns intelectuais. Mas talvez nada tenha sido menos estudado do que como a colonização subjuga o conhecimento e marginaliza as epistemes locais (OYĚWÙMÍ, 2016a, p. 1).

No contexto do trabalho com as filosofias africanas, precisamos nos questionar o que significa descolonizar as lógicas de conhecimento. A busca por responder a esta questão nos demanda perceber que o tema da descolonização acompanha a teorização sobre o fazer filosófico em cenários políticos e teóricos que assumem sentidos variados desde, pelo menos, a metade do século XX. A teoria 
crítica, os estudos pós-coloniais, os estudos subalternos, os estudos sobre colonialidade - entre outras abordagens que tematizaram a descolonização do pensamento, do conhecimento ou da filosofia - se difundiram e seguem se difundindo com objetivos, alcances e sentidos que variam tanto quanto se modifica o entendimento do que seja a colonização do conhecimento e seus impactos.

Seguiremos, aqui, a interpretação de Oyèrónkẹ Oyěwùmí sobre o que significa descolonizar. Para nossa autora, além do efeito político de subordinar e explorar territórios e povos, a colonização operou na subjugação, na marginalização e na desconsideração dos modos de conhecer dos povos colonizados. Mesmo em parte considerável dos chamados Estudos Africanos, as experiências, saberes e culturas dos povos do velho continente negro são tomadas apenas como objetos de investigação, nunca sendo consideradas como matrizes a partir das quais o conhecimento seja produzido, ou seja, desconsiderando as lógicas africanas de conhecimento nas próprias investigações sobre África.

Em seus estudos direcionados a leituras críticas das epistemologias do gênero utilizadas nos estudos africanos, mais especificamente sobre as sociedades iorubás, nossa autora percebeu que da "perspectiva da produção de conhecimento, as categorias de conhecimento iorubás - as maneiras pelas quais a cultura codificou e organizou a informação — em geral, tendiam a não influenciar as afirmações e conclusões das pesquisas" (OYĚWÙMÍ, 2016a, p. 2).

Por isso, Oyěwùmí (2016b) é enfática ao afirmar que, para ela, “descolonizar é endogenizar, autoctonizar, historicizar". Com isso ela aponta para a necessidade não apenas de considerar como válidas as experiências africanas, a partir das abordagens ocidentocêntricas das lógicas de conhecimento, mas, também, situar as lógicas ocidentais, provincializando-as (OYĚWÙMÍ, 2016a, p. 4). Essa provincialização das lógicas de conhecimento ocidentais busca fazer notar que os modos pelos quais o ocidente produz conhecimento são localizados em suas próprias experiências históricas, marcados pelas tramas políticas, econômicas, espirituais e coloniais nas quais estão envolvidos. Com isso, a autora recusa um pressuposto básico de muitas pesquisas, a saber, que não apenas algumas das categorias ocidentais utilizadas nas investigações sobre África são universais, como também que o próprio solo cultural 
no qual tais categorias emergem o sejam. Sobre essa dimensão do trabalho de Oyěwùmí, nos ensina a filósofa sul-africana Azille Coetzee (2017, p. 40):

Seu trabalho sugere que os conhecimentos e realidades africanas são subsumidos e apagados pelos conhecimentos e realidades ocidentais porque os conhecimentos e realidades ocidentais são erroneamente considerados como representantes do universal.

Assim, buscar localizar, situar, provincializar os modos como as pesquisas são feitas, tanto lastreando a história da maneira como chegamos a pensar e pesquisar como pensamos e pesquisamos, quanto com a crítica do apagamento das lógicas de conhecimento africanas são passos fundamentais para a descolonização epistêmica. A recusa da presunção do universal é um dos começos. Nesse contexto, o universal não é apenas vinculado com os conteúdos das categorias, mas também com o próprio fazer da investigação, que carrega sua própria lógica de conhecimento. Com isso afirma-se que não se trata apenas de não utilizar, como se necessárias fossem, as categorias ocidentais, mas de perceber que as maneiras como percebemos as experiências que investigamos podem também reproduzir um ethos epistêmico que opera no silêncio da universalidade, apagando as lógicas de conhecimento das sociedades em torno das quais investigamos.

Esta compreensão dos modos como percebemos, sob a égide da condução ocidental das maneiras de produzir conhecimento, se relaciona com a necessidade de entender como os domínios político e epistêmico se entrelaçam: "Sem atenção ao domínio material global do Ocidente, não pode haver uma compreensão ajustada para sua hegemonia contínua nas ideias e na produção de conhecimento. Por isso, este estudo é, também, sobre a sociologia do conhecimento" (OYĚWÙMÍ, 1997, p. xi).

Com este alerta, poderemos estar atentas para a necessidade de perceber as maneiras como lidamos com as experiências de pensamento africanas; não poderemos simplesmente lidar com as filosofias africanas da mesma maneira como lidamos com as filosofias ocidentais, a não ser que tomemos as primeiras como meros objetos. Assim, somos levadas a diferenciar um estudo ocidentocêntrico das filosofias africanas de uma prática descolonizada da filosofa africana, realizada em seus próprios termos, partindo de suas próprias lógicas de conhecimento, modos de fazer e sentidos atribuídos pelas práticas africanas forjadas no próprio enfrentamento colonial. Isso 
não nos encaminharia a um acesso a um pensamento africano puro ou a uma essência do pensar africano, mas nos conduziria a experiências que foram - e são construídas no continente africano na busca de entender o que lhes fora imposto colonialmente e o que lhes é autóctone.

\section{Um pensamento oxunista}

As ferramentas do senhor nunca derrubarão a casagrande (LORDE, 2019, p. 152).

Na senda da descolonização das lógicas de conhecimento, tal como apontado por Oyěwùmí, nos encontramos diante de uma série de outros desafios. Provincializar as lógicas ocidentocêntricas de conhecimento exige de nós um deslocamento sobre nossa própria história, pois fomos ensinadas a pensar e a produzir conhecimento de uma maneira localizada, mas enunciada como universal. No que diz respeito ao trabalho com as filosofias africanas seremos, então, levadas não a ter apenas os conteúdos dessas filosofias como experiências a serem pensadas, mas nosso próprio modo de pensar como viemos aprendendo e ensinando a filosofia também como alvo constante de nossa investigação e problematização.

A partir das provocações de Oyěwùmí, podemos imaginar algumas ferramentas que nos auxiliem a lidar com esses desafios. $\mathrm{Na}$ conferência de encerramento do Seminário Internacional Decolonialidade e Perspectiva Negra, ocorrida em Brasília, em 2016, a autora enfrenta, novamente, o problema da hegemonia ocidental nos estudos africanos, nos convocando a considerar as epistemes locais africanas como substratos fundamentais para as lógicas de conhecimento. $\mathrm{Na}$ busca de, nesse contexto, não ser obrigada a utilizar os feminismos como ferramenta única para pensar as experiências das mulheres africanas, a autora nos inquieta com a seguinte afirmação:

Para além da ruptura epistêmica que deve acontecer com o feminismo, também deverá haver uma ruptura linguística. Deverá haver uma renomeação. Acredito que deva haver ligações com o que viemos pensando. Por que não posso chamar meu ativismo, minha mobilização de oxunismo? [...] Em todo o continente [africano], as epistemologias subjugadas apontam certas maneiras para que possamos olhar para esse fenômeno. Mesmo a história da origem humana, em muitas outras culturas, começa com Iyá, começa com Oxum, começa com a Mãe da Humanidade. E por que ela não está no centro do poder? Observem... Então, hoje, proponho o oxunismo. Para mim, sua definição é 
mobilização, ativismo, que prioriza İyá, Mãe e sua prole. Mobilização em nome de İyá, priorizando İyá. E sua prole. E isso é inclusivo, porque todo mundo nasce de uma İyá (OYĚWÙMÍ, 2016b).

Esta provocação aparece em meio a sua crítica à universalização da categoria de gênero como instrumento privilegiado para o estudo das sociedades africanas précoloniais, e, em especial, as sociedades iorubás (FLOR DO NASCIMENTO, 2019). Sua contundente tese de que o gênero não era uma categoria de organização social entre os povos iorubás anteriores à colonização europeia faz com que ela suspeite de uma tendência naturalizada de leitura das experiências das mulheres africanas hoje apenas através das lentes dos feminismos, que se firmaram na atualidade como estruturados em torno de problematizações sobre a categoria de gênero.

Nessa busca de uma ruptura epistêmica e linguística com as heranças coloniais, marcas de seu esforço por uma descolonização das lógicas de conhecimento, Oyěwùmí propõe o oxunismo como movimento que seja capaz de ler as experiências das mulheres africanas na resistência à imposição do gênero pelo patriarcado colonial. O nome desta proposta deriva da orixá Oxum, divindade iorubana vinculada com a primogenitura da humanidade (OYĚWÙMÍ, 2016a).

Nossa autora retoma as representações autóctones desvencilhadas das imagens coloniais desta divindade para nos apresentar uma sociedade na qual a figura de Oxum encarna — na interpretação da autora, sem generificação — potências de uma subjetividade e de uma organização política em que a liderança comunitária, a espiritualidade organizadora — metafísica e politicamente —, a criação inventiva, a responsabilidade pelo coletivo e a ausência de binarismos hierárquicos, seja na política seja na produção do conhecimento.

Oxum é, para Oyěwùmí, marca da presença de outra percepção de realidade, de organização social e de resolução de conflitos que os povos iorubás do sudoeste da Nigéria cunharam a partir de seus próprios marcos históricos. A divindade é a İyá primordial que, como veremos, se distingue da ideia ocidental hegemônica de mãe, embora o vocábulo iorubá seja rotineiramente traduzido como "mãe”. Signo expansivo, criativo, dinâmico como o fluxo das águas nas quais a divindade se presentifica, percebemos em Oxum a potência criadora e mantenedora da humanidade que, generosamente, materna coletivamente o mundo. É doadora de vida. 
O termo oxunismo aparece, no cenário teórico, com a filósofa nigeriana Nkiru Nzegwu (2011a), que lê em Oxum um erotismo criativo e não subordinante, percebendo na força da divindade a energia criativa, à qual ela chama de oxunalidade (NZEGWU, 2011b, p. 258). Oyěwùmí, ampliando a categorização de Nzegwu para o campo do ativismo político, aposta na figura de Oxum como orientadora da ação coletiva que reivindique os modos iorubás de perceber o conhecimento sobre a ação, sobre a política, que entenda Oxum como força criadora, expansiva e política, mas também como um marcador do conhecimento. Em sua tradução de alguns dos versos de uma das narrativas iorubás de Ifá — um sistema tradicional de conhecimento —, Oyěwùmí nos apresenta, assim, a divindade: "Ofereçamos o conhecimento para a fêmea, nossa İyá que encarna o conhecimento. Chamemos o conhecimento de Oxum, nossa İyá que encarna o conhecimento" (OYĚWÙMÍ, 2016a, p. 57).

É neste encontro entre a movimentação política do oxunismo e a faceta de Oxum como aquela que encarna o conhecimento que podemos pensar que, no interior deste oxunismo, opera, de maneira potente, um pensamento oxunista. Esse pensamento traria consigo as características expressas por Oxum, em sua dimensão de İyá da comunidade, de mãe da humanidade, de potência criadora, inventiva, não excludente, guerreira, negociadora. Um pensamento oxunista percebe os riscos que o cercam, sobretudo os riscos coloniais, que são sedutores, e se afirma com a sagacidade de Oxum, que, entre o poder e o conhecimento, se recusa a ser subjugada.

Um pensamento oxunista opera na lógica do isso também e não na lógica binária excludente do ou isso ou aquilo, porque Oxum, na interpretação de Oyěwùmí, "é o signo da diferença" (2016a, p. 53). Essa dimensão apresenta Oxum no campo da disputa inclusiva e não para o dissenso que exclui. Por isso, tal pensamento oxunista seria um pensamento expansivo e inclusivo (no sentido de não excludente), porque dele depende todo o restante da reflexão que venha a seguir. Por outro lado, é um pensamento responsável — como responsável é a mãe pela vida e provisão de sua prole, mantendo com ela um vínculo inquebrantável, mesmo diante da morte. É um pensamento que carrega a potência criativa, inventiva, expansiva e cuidadora, engajado em fortalecer tudo que dele descenda, sem entrar em uma sanha destrutiva, pois sabe que da diferença o mundo é feito. Assim, um pensamento oxunista é um pensamento da diferença nos 
termos que a tradição iorubá confere ao modo de pensar, agir e produzir conhecimento, tendo Oxum como seu signo matripotente máximo.

Além disso, Oxum é a mais antiga das primeiras divindades a virem para a terra, por ser a mãe da humanidade e também das demais divindades que vieram com ela para esta dimensão do mundo (OYĚWÙMÍ, 2016a, p. 51), sendo assim a fonte do poder de todas elas. Isso porque, para as sociedades iorubás, a senioridade é o eixo de estruturação do poder e do prestígio (OYĚWÙMÍ, 1997) e, também, da responsabilidade.

\section{İyá e matripotência, caminhos descolonizadores}

İyá está no centro do sistema baseado na senioridade, que simboliza o que descrevo como princípio matripotente. A Matripotência descreve os poderes, espiritual e material, derivados do papel procriador de İyá. A eficácia de İyá é mais acentuada quando considerada sua relação com a prole nascida. $O$ ethos matripotente expressa o sistema de senioridade em que Iyá é sênior venerada em relação a suas crias. Como todos os humanos têm uma İyá, todos nascemos de uma İyá, ninguém é maior, mais antigo ou mais velho que İyá. Quem procria é a fundadora da sociedade humana, como indicado em Oseetura, o mito fundador iorubá (OYĚWÙMÍ, 2016a, p. 58-59).

Já chamamos a atenção para a tradução de İyá como mãe. Entretanto, é preciso situar o contexto da problematização que Oyěwùmí traz sobre essa tradução. Uma das leituras hegemônicas ocidentais sobre a mãe apresenta-a como uma figura subordinada ao pai/esposo e à prole, "sempre coagida pelo poder patriarcal" (FIDALGO, 2005, p. 119). No entanto, para a cultura iorubá prévia à colonização, İyá, a progenitora, a mãe, não é subordinada nem à prole e nem ao parceiro sexual. Em função da senioridade, ela ocupa sempre um status superior à prole. E não é sujeita ao companheiro sexual na relação de geração da prole e nem está em oposição a ele (OYĚWÙMÍ, 2016a, p. 66). Quando pensada diante desta moderna e colonial imagem prevalente da mãe, como "incorporada por mulheres que são esposas subordinadas, fracas, impotentes e relativamente marginalizadas socialmente" (OYĚWÙMÍ, 2016a, p. 58), İyá é uma mãe não colonial, que encarna o ethos matripotente advindo de Oxum. A Matripotência é entendida pela autora como a 
"supremacia da maternidade" (OYĚWÙMÍ, 2016a, p. 7), maternidade esta entendida partindo dos registros iorubás não coloniais. Acima de tudo, İyá é uma instituição sócio-espiritual que, mesmo ligada com a procriação que passa pelo corpo de uma fêmea anatômica, é uma experiência coletiva e um ethos de gestão social:

Em um mundo de possibilidades para todos os nascidos de İyá, a ideologia materna, orientada para a comunidade, totalmente inclusiva, doadora, sustentadora e preservadora da vida, pode fornecer a direção e a base para a ação política e a transformação social necessária (OYĚWÙMÍ, 2016a, p. 220).

Oyěwùmí nos apresenta a matripotência como o modo autóctone iorubá de pensar a experiência na qual as mães exercem suas maternidades fora dos registros patriarcais de gênero que o ocidente insiste em imprimir nas experiências africanas. Desta maneira, a matripotência é um conceito oxunista que a autora nos apresenta para estudar as experiências iorubás sem apelo aos registros patriarcais da experiência da procriação e considerando as consequências políticas de uma organização social em torno dessa percepção da realidade na qual İyá ocupa um lugar central.

Nesse exercício, Oyěwùmí (2016a, p. 59-78) nos apresenta as características matripotentes de İyá: vínculo metafísico com sua prole, sendo indefinidamente responsável por ela, uma vez que ela é, junto com a divindade da criação dos seres humanos, a co-criadora, produtora de beleza e bom-caráter, multiplicadora da comunidade e da própria humanidade, liderança política, fonte da ideia de solidariedade, de provimento material e moral.

Mas é o caráter absolutamente coletivo da instituição İyá que a torna um caminho descolonizador para as reflexões sobre as experiências africanas. Ela nos afirma que compreender a instituição da "maternidade e de sua posição única na sociedade iorubá pode auxiliar na luta para a transformação na vida de todos os africanos" (OYĚWÙMÍ, 2016a, p. 211), entendendo essa transformação como uma experiência de descolonização.

Ela percebe na matrifobia [matrophobia] — entendida como medo do "tornar-se mãe" (OYĚWÙMÍ, 2016a, p. 213) de alguns discursos feministas ocidentais uma dessas forças despotencializadoras coloniais das experiências africanas. Isso porque não é apenas a experiência particular de uma mulher que deseja ser mãe que é recusada pela matrifobia, mas de todo esse ethos matripotente que fortalece a comunidade em torno 
de İyá. Se junto da mãe moderno-colonial (subordinada pelo patriarcado) se recusa İyá, recusa-se uma importante esfera sócio-espiritual iorubá, apagando a percepção iorubá de uma "construção matricêntrica do sujeito e do mundo" (COETZEE, 2017, p. 59).

Reconhecer a dimensão matripotente como caminho descolonizador aponta para o fortalecimento da relação İyá/prole que retoma uma estruturação da sociedade e dos sujeitos de maneira não unitária, não binária e sempre coletiva. İyá é sempre ela $e$ sua prole. A prole é sempre composta pelo axé, força fundamental, de İyá. Assim como Oxum é o signo da diferença, İyá é o signo dessa diferença que assume a forma de uma relação com o restante do mundo. Se se quiser utilizar a categoria da alteridade, é possível afirmar que:

O sujeito relacional da sociedade iorubá está, antes de mais nada, sempre e inevitavelmente em relação com a mãe. Consequentemente, o sujeito não é singular e unificado, não tem limites claros que o separam do que é outro. A alteridade não é entendida como antitética ao si mesmo, mas parte do si, porque este existe, principalmente, em relação com a mãe/outro ${ }^{1}$ (COETZEE, 2017, p. 60).

Essa diferença múltipla em torno de İyá oferece marcos para a compreensão da experiência iorubá que contornem hierarquizações que foram responsáveis por aprisionar a subjetividade desses povos, de maneira a sujeitá-los à marcha do progresso ocidental sob a justificativa de que eram o lado inferior de uma dicotomia hierarquizada. A matripotência, desse modo, apresenta facetas do mundo social iorubá que vedam a possibilidade dessa interpretação colonial.

Dessa maneira, İyá dissolve diversas dicotomias que tornam inteligíveis ideias que operam nas lógicas ocidentocêntricas de conhecimento, como as dicotomias eu/outro, matéria/espírito, natureza/cultura e mesmo a distinção dicotômica entre masculino/feminino, já que, para os iorubás, não há uma contraparte na relação com İyá, o pai não ocupa uma posição comparável, pois a relação na qual ela surge é com a prole e não com o parceiro sexual (COETZEE, 2017, p. 123-130). É em função disso que Oyěwùmí (2016a, p. 61) afirma que "no momento do nascimento, duas entidades surgem — um bebê e uma İyâ’.

\footnotetext{
${ }^{1}$ A autora faz um jogo de palavras, em inglês, impossível de traduzir ao português: ( $m$ )other, apontando tanto ao caráter de mãe, mother, quanto ao caráter de outro, other.
} 
Assumir a categoria oxunista de matripotência e sua fonte, İyá, nos fornece instrumentos para lidar com as armadilhas ocidentocêntricas que reduzem o diferente ao mesmo na forma de um binário hierarquizado. Seja pensando as questões de gênero, a epistemologia, a política, a metafísica ou qualquer outro campo envolvido nas reflexões de Oyěwùmí, observamos o cuidado em tomar a sério as experiências africanas em seus próprios termos e em seu próprio solo cultural. A matripotência aqui é a recusa em descrever experiências africanas através de categorias que sigam lógicas ocidentocêntricas de conhecimento que resultam por inscrever os povos africanos em uma hierarquia existencial, subordinada e subordinante.

Ao apresentar İyá e a matripotência como instituições e ethos comprometidos com as experiências africanas, o caminho da descolonização se coloca, para a proposta de Oyěwùmí, como saída para uma tutela das experiências africanas pelos modos ocidentais de produção de conhecimento que findam por informar políticas internacionais - e mesmo políticas internas colonizadas — sobre os modos como devemos lidar com as sociedades africanas. Essa estratégia oxunista de descolonização se recusa a enxergar o continente africano como “órfão” (OYĚWÙMí, 2016a, p. 214), como sem mãe, quando a base da organização social pode ser descrita em torno da agência da instituição İyá.

Em tempos de sequestro da matripotência africana, İyá Oxum aparece como um importante signo descolonizador, nos convocando a nos posicionarmos como herdeiras de sua progenitura, aprendendo com o passado, para transformar o presente. Não se trata de uma idealização do passado, mas de, estrategicamente, assumirmos nossa ancestralidade como presente em nós, apesar de todas as tentativas coloniais de borrá-la. Nesse contexto, o pensamento oxunista é, sempre, uma reivindicação ancestral.

\section{Considerações finais}

Ao trazermos a discussão sobre a descolonização das lógicas de conhecimento tal como Oyěwùmí a propõe, demandando um compromisso com as próprias lógicas africanas de conhecimento, temos muito a ganhar no contexto da produção brasileira em torno das filosofias africanas. Se considerarmos o trabalho com as filosofias 
africanas em nosso país de maneira análoga à pressuposição da autora de que as mulheres foram inventadas — e com isso, vimos a transformação das fêmeas anatômicas em seres subordinados à lógica patriarcal — na Iorubalândia moderna e como, nesse processo, os modos de produção de conhecimento desempenharam papéis fundamentais na captura e no apagamento das lógicas de conhecimento autóctones e das instituições sociais anteriores à colonização, podemos nos perguntar se nosso fazer, mesmo bem intencionado, não opera de modo semelhante inventando entidades nos mundos africanos que queremos conhecer, ao aplicar sobre eles lógicas de conhecimento forâneas.

Essa questão deveria nos colocar sob alerta constante, pois algo que aprendemos com várias abordagens negras no mundo é que o processo colonial segue tentando nos moldar a suas maneiras de funcionamento. Um passo fundamental para a busca da descolonização de nossas lógicas de conhecimento implica perceber que a colonização persiste, não é algo do passado e, portanto, nossas ferramentas conceituais muitas vezes estão comprometidas com essas lógicas de conhecimento coloniais.

Perceber isso nem sempre é tarefa fácil. Fomos subjetivadas para pensar que as lógicas de conhecimento forjadas no conhecimento não apenas são universais, como são o melhor caminho para o progresso do pensamento e da própria filosofia. Muitas vezes pensamos que basta mudar, trocar as lentes por meio das quais observamos a experiência filosófica, incluindo conceitos africanos em nossas pesquisas, mas operando do mesmo modo como fomos ensinadas desde o começo da modernidade.

Mas a provocação de Oyěwùmí nos leva mais longe. Não basta apenas essa ruptura epistêmica com os conceitos, mas também com as lógicas de conhecimento. Não basta trocar as lentes, mas perceber que as lentes e os modos como estas são usadas também têm uma história, também emergem de solos culturais e de projetos políticos que nascem em algum lugar e que podem nos parecer universais. A própria metáfora da lente nos mostra o quanto estamos confortáveis com a lógica ocidentocêntrica de conhecimento, pois nos mundos iorubás, e em vários outros mundos que nos cercam, muitos são os sentidos, além da visão, que são acionados na produção do conhecimento, como bem nos lembra Oyěwùmí (1997). 
Entretanto, isso não significa que devamos nos livrar das lentes que herdamos — a matripotência é inclusiva! O que precisamos é estar atentas às histórias carregadas pelas lógicas de conhecimento das quais nos servimos e, sobretudo, perceber o quanto de silenciamento, de apagamento essas lógicas promovem. Evocando outra divindade iorubana conhecida por Oyěwùmí, Ogum — a divindade iorubana da tecnologia e da guerra -, podemos pensar que nosso trabalho com as filosofias africanas precise considerar a maior quantidade possível de ferramentas. Mas, assim como a divindade ferreira, precisamos conhecer as histórias dessas ferramentas, de onde elas vêm, ao que e para que elas servem, para que possamos destinar a elas outras utilizações, não coloniais.

Pensar sobre essas questões, no Brasil, que foi constituído em uma ambiência filosófica que reconhece apenas uma matriz de produção da filosofia - mesmo que tenha uma abertura cada vez maior para as várias tradições filosóficas do mundo, desde que se adequem ao modus operandi do fazer filosófico que nomeia o campo - é um imenso desafio, para o qual precisamos estar atentas permanentemente. Quem sabe ao deixarmo-nos tocar por esse saber ancestral de İyá, sempre coletivo, sempre atento aos conflitos internos à comunidade, estejamos mais próximas de caminhos mais potentes rumo à descolonização, do pensamento e de nossa própria vida.

\section{Referências}

COETZEE, A. African feminism as decolonising force: a philosophical exploration of the work of Oyèrónké Oyěwùmí. 2017. Orientadora: Louise du Toit. Tese (Doutorado em Filosofia) Faculty of Arts and Social Sciences, Stellenbosch University, Cidade do Cabo, 2017.

FIDALGO, L. Mãe. In: MACEDO, A. G; AMARAL, A. L. (orgs.). Dicionário da crítica feminista. Porto: Afrontamento, 2005. p. 119-120.

FLOR DO NASCIMENTO, W. Oyèrónkẹe Oyěwùmí: Potências filosóficas de uma reflexão. Problemata: Revista Internacional de Filosofia, v. 10, n. 12, p. 8-28, 2019.

LORDE, A. Irmã outsider: Ensaios e Conferências. Belo Horizonte: Autêntica, 2019.

NDLOVU-GATSHENI, S. Coloniality of Power in Postcolonial Africa. Myths of Decolonization. Dakar: Codesria, 2013.

NZEGWU, N. Transfixing Beauty: The Allure of Maiden Bodies. West Africa Review, n. 18, p. 1-28, 2011a. 
NZEGWU, N. Osunality. In: TAMALE, S. (ed.). African Sexualities. A Reader. Oxford, Nairobi, Dakar, Cidade do Cabo: Pambazuka/Fahamu, 2011b. p. 253-270.

OYĚWÙMÍ, O. The Invention of Women: making an African sense of western gender discourses. Minneapolis: University of Minnesota Press, 1997.

OYĚWÙMÍ, O. What Gender is Motherhood? Changing Yorùbá Ideals of Power, Procreation, and Identity in the Age of Modernity. Nova Iorque: Palgrave, 2016a.

OYĚWÙMÍ, O. Desaprendendo lições da Colonialidade: Escavando saberes subjugados e epistemologias marginalizadas. In: SEMINÁRIO INTERNACIONAL DECOLONIALIDADE E PERSPECTIVA NEGRA, Brasília, 2016b. Disponível em: https://www.youtube.com/watch?v=zeFI9vTl8ZU. Acesso em 14 dez. 2020. 